\title{
Low literacy Chinese patients: how are they affected and how do they cope with health matters? A qualitative study TP LAM*1, YH CHENG ${ }^{2}$ and YL CHAN 1
}

Address: ${ }^{1}$ Family Medicine Unit, Department of Medicine, The University of Hong Kong, Hong Kong, China and ${ }^{2}$ Department of Community Medicine \& Unit for Behavioural Sciences, The University of Hong Kong, Hong Kong, China

Email: TP LAM* - tplam@hku.hk; YH CHENG - hrmrcyh@hkucc.hku.hk; YL CHAN - chanyuklan@graduate.hku.hk

* Corresponding author

Published: 04 May 2004

BMC Public Health 2004, 4:14
Received: 14 February 2004

Accepted: 04 May 2004

This article is available from: http://www.biomedcentral.com/I47I-2458/4//4

(c) 2004 LAM et al; licensee BioMed Central Ltd. This is an Open Access article: verbatim copying and redistribution of this article are permitted in all media for any purpose, provided this notice is preserved along with the article's original URL.

\begin{abstract}
Background: Low literacy is common in Hong Kong and China, especially among the females and the elderly. These are often the patients with the greatest health care needs. However little is known about how low literacy affects the ability of patients to obtain adequate medical care and comply with the recommendations of health professionals.
\end{abstract}

Methods: Qualitative study of subjects' opinions using semi-structured group and individual interviews. Thirty-six participants took part in 6 group and 9 individual interviews.

Results: Participants' opinions towards low literacy were explored in the interviews. They expressed diverse views on how they perceived low literacy. Some thought they were handicapped by it but others felt it was not a problem. Age, gender, chronic illnesses and their attitudes towards self were found to be major factors affecting their perception. Despite their low literacy, some had their specific ways to overcome the difficulties, for example, drawing symbols to help with the timing of taking the medications. Most of them felt better explanation by the health care workers was most important.

Conclusions: It is highly relevant for health care workers to be aware of the low literacy status of their patients and to explain information so that patients understand it.

\section{Background}

In the 2001 Hong Kong Population Census [1], 8.4\% of the population aged 15 and over had either no schooling or only kindergarten level of education. This is particularly so among the females with $12.0 \%$ of them belonging to that category versus $4.6 \%$ of the males within the same age group. Low literacy is also found to be more common among the older populations. Among the 55 and over, $31.2 \%$ had either no schooling or only kindergarten level of education.
This shows that a significant number of the population had no or minimal level of education, particularly among the females and the elderly. The latter also tend to suffer from more chronic illnesses. This group of low literacy people are also more likely to belong to the population of the lower socio-economic groups. This group is the major user of Hong Kong's public hospitals and clinics. The ways these people utilise the public health care facilities will have a major impact on the efficiency of the system. 
Low literacy may be an important barrier to receiving adequate health care, because patients must be able to understand appointment slips, medicine labels, directions for self-care, informed consent forms, and health education material[2]. In US, it was showed that low literacy is associated with worse health according to the Sickness Impact Profile, although the reasons for this are unclear [3]. Many other studies in the US have also showed that the medical information routinely given to patients is often above their reading level [4-6]. In 1999, a Committee of the American Medical Association stated that patients with the greatest health care needs might have the least ability to read and comprehend information needed to function successfully as patients [7]. However, there is little information available on how low literacy affects the ability of patients to obtain adequate medical care and comply with the recommendations of health professionals $[8,9]$.

In Hong Kong, there is no knowledge on the relationship between low literacy and health outcomes, despite the large number of people with low literacy in the community. Furthermore, the trend of international migration in recent decades means that health professionals in developed countries are quite likely to see patients of different ethnic origins [10] including overseas Chinese who may not have adequate command of the local languages. The findings of this study should therefore be of interest to those health care workers who look after Chinese patients with limited literacy of the local languages in different parts of the world.

This study adopted a qualitative approach to interview the participants in order to collect in-depth data to understand their experiences when interacting with the health care system. Their stories provide accounts of difficulties, coping mechanisms, and sensitivity to the issues of low health literacy.

\section{The local health care system}

Hong Kong's health care delivery system is structured around general family practice, with specialist support available both privately and through public hospitals. The latter, however, take care of $97 \%$ of total in-patients in Hong Kong and the remaining by other private hospitals. All registered doctors are Western-trained in Hong Kong. Private general practitioners provide $75 \%$ of primary care, while government salaried doctors provide $15 \%$ and the rest $(10 \%)$ by other healthcare providers, such as Traditional Chinese Medicine practitioners. The patients freely choose their own health care providers for their illnesses. In 2003, there were about 9000 registered doctors. It was estimated that more than 4000 doctors worked in public hospitals and clinics, and 4000 in private practices in the community. Most of the others probably spend most of their time outside Hong Kong but continue to be regis- tered. In the past, most of the primary care doctors did not receive any formal postgraduate vocational training in general practice/family medicine but this is rapidly changing with general practice/family medicine being the largest training discipline for junior doctors now.

One of the authors (TPL) works in a public primary care clinic which mainly caters to the socially disadvantaged and is heavily subsidized by the government. The patients pay US\$5 for each consultation, inclusive of laboratory investigations and medications prescribed.

\section{Methods}

Participants

Participants were recruited from the clinic where one of the authors (TPL) works and is situated in the southern side of the Hong Kong Island. The method of selecting the participants is detailed in Figure 1. Patients with low literacy but different demographic variables were purposively sampled for the study. Our experiences working at the clinic revealed that almost $30 \%$ of the attenders, particularly the elderly female patients are of low literacy level. Despite a large number of adult residents never attended formal education in Hong Kong; there is no established definition of low literacy. (Personal communication, Dr MS Chan, Department of Chinese, The University of Hong Kong) Their reading skills were therefore tested to ensure that their literacy level was no more than that of Grade One primary school level. Table 1 shows that more females participated in the study because more female patients attend the clinic and are more representative of the population with no schooling or only a kindergarten level of education.

Table I: Age and sex of participants

\begin{tabular}{cccc}
\hline $\begin{array}{c}\text { Number of participants } \\
\text { focus group: }\end{array}$ & 27 & & \\
individual: & 9 & & \\
Total: & $\mathbf{3 6}$ & & \\
Age & focus group & individual & Total \\
$30-39$ & 1 & 1 & $\mathbf{2}$ \\
$40-49$ & 0 & 0 & $\mathbf{0}$ \\
$50-59$ & 1 & 1 & $\mathbf{2}$ \\
$60-69$ & 14 & 3 & $\mathbf{1 7}$ \\
$70-79$ & 6 & 2 & $\mathbf{8}$ \\
$80-89$ & 5 & 2 & $\mathbf{7}$ \\
Sex & focus group & individual & Total \\
male & 4 & 4 & $\mathbf{8}$ \\
female & 23 & 5 & $\mathbf{2 8}$ \\
& & & \\
\hline
\end{tabular}

Six group interviews and nine individual interviews were conducted between November 1999 and May 2000. Group interviews consisted of up to four participants. A 
small number of the participants were actually noted to be slightly inhibited in group interviews. Both group and individual interviews were therefore conducted in order to maximize the range of data collected. This qualitative approach also ensured the quality of the data collected as it provided the time required to establish trust between the interviewer and the interviewees. Furthermore, it provided the time to suit the usual communication style of many of the participants who tended to give rather long and unstructured descriptions of their experiences and opinions. A mature female research assistant (YLC) with extensive experience in qualitative research was trained to conduct these interviews using the local Cantonese language at one of the authors' office. In order to minimise the possible effects of the interviewer may have on the patients, an interviewer without medical background was recruited. She was presented to the participants as an "assistant in research" for the authors and was well received. Each interview lasted for one to one-and-a-halfhours. The participants were encouraged to tell their story and express their opinions but an interview protocol was used to ensure all relevant domains were covered. These included participant views on the adverse effects of low literacy on their medical care, their experiences and how they coped with the difficulties. They were also asked to suggest ways the health care system could help patients with low literacy.

This study was approved by the Ethics Committee of the Faculty of Medicine of the University of Hong Kong.

\section{Translation and transcription}

The tape-recorded interviews were transcribed verbatim into Chinese by the research assistant (YLC) and were checked by TPL who listened to the recording while checking the accuracy of the transcripts. Selected texts were then translated into English when this paper was being drafted.

\section{Analysis}

Transcripts were analyzed using NUD*IST software and a grounded theory approach [11]. The complete texts of the interviews were entered onto the database and they were then coded into broad themes. The objective of the analysis was to identify provisional inferences from the texts. The software, NUD*IST, with its powerful cross-linking capacities allowed consideration of all relevant texts and easy modification of the broad themes. The consistency and validity of analysis and interpretation was assessed by having five randomly selected interview transcripts independently coded by two experienced qualitative researchers. The results were compared and there were no significant inconsistencies. The interpretation of the data was also discussed with five randomly selected participants who had been interviewed to compare our perspec- tives with that of the participants. This process again revealed no significant corrections of our interpretation.

\section{Results}

Participants expressed rather diverse views on how they perceived low literacy. Some thought they were handicapped by it. However many others felt it was not a problem, or just a rather minor problem.

\section{Low literacy is a problem}

For those who felt low literacy was a problem, concerns often centered around medicine taking. They might have taken their medicines at the wrong time or with wrong doses.

Chan 1: I just took it casually. After having 'dim sum' for breakfast, at around nine o'clock or ten, I took the first dose. Then I took the second dose at two or three o'clock in the afternoon. I took more than ten tablets within four or five hours. The doctor scolded me, "Why have you not got well even after such a long period of time? How do you take your medicines?" I told him that I took the medicines after breakfast, earlier if I did not have to prepare lunch, and a bit later (at ten o'clock) if I had to do so. Then I took the other dose at two o'clock [in the afternoon]. He said, "You are so lucky that you did not die of that! " I took all the tablets within five hours!

Interviewer: What were those medicines for?

Lau 1: Did anything bad happen to you?

Ko 1: Was it because you have forgotten [about the time]?

Chan 1: No. I was only being ignorant.

(Focus Group 1, text units 116-120)

Others also had difficulty locating the medical institutions or a particular place of the institutions that they had to visit. As a result, they might try to avoid going to unfamiliar places for their medical attention. However, for medical emergencies, their low literacy made them more nervous because they would not be able to wait for a friend or a relative to accompany them, nor have the time to ask other people. Furthermore, they felt some medical personnel looked down upon them because of their poor literacy which made them feel even worse.

\section{Low literacy is not a problem}

There were however some participants who felt their low literacy did not pose a particular problem as far as their health was concerned. Some felt they had successfully relied on their memory to cope and had not experienced particular difficulties. As for medicine taking, they 


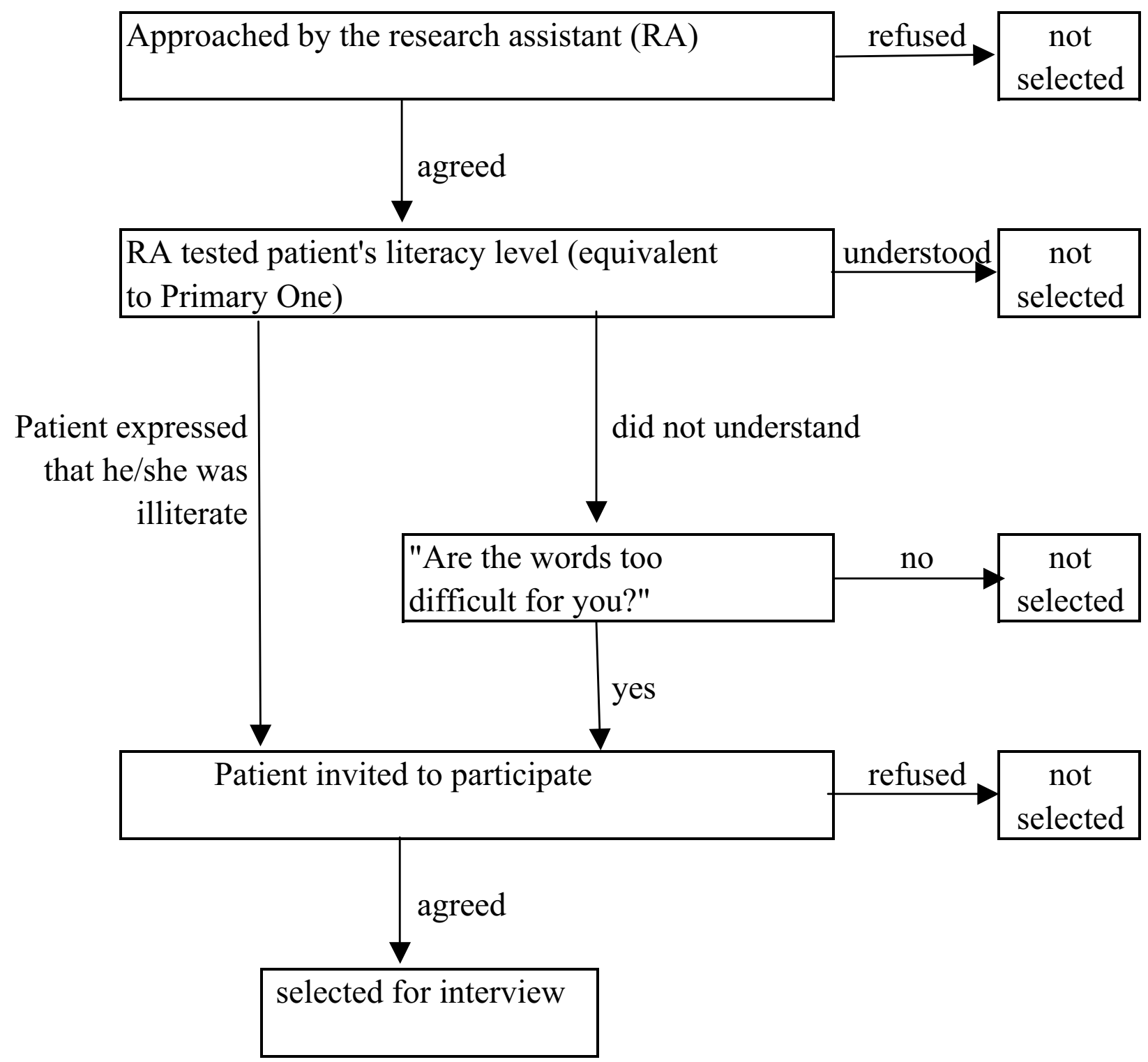

Figure I

Flowchart for selecting project participants.

thought it was easier with medications for chronic conditions. They could also recognize a few important "symbols" for example " 1 or 2 " to help them cope. Even if they were not able to read the labels at all, they thought there would always be someone to help. Some also expressed that, despite incidents of not taking the medicine correctly, they did not seem to bring any significant harms!
Interviewer: Do you think it is a problem that you can't read the instructions on the packages of the medicines?

Lee 1: I would ask my children to read it for me.

Ma 1: Surely we would ask them to read it for us. Even if they had already gone to bed, we had to wake them up. I couldn't care. 
Lee 1: There were indication marks on the bottle of the medicines. I poured it into a spoon.

Interviewer: You would rely on those marks.

Lee 1: Yes.

Interviewer: But how did you know when to take the medicines?

Lee 1: For those that had to be taken once in four hours, I took them every four hours. For the three-hour ones, I took them every three hours.

Interviewer: Was it something they [the medical staff] told you?

Lee 1: I couldn't read it, and would ask my family members to read it for me.

(Focus Group 2, text units 249-258)

\section{Factors affecting their perception}

The perception of low literacy being a problem or not was found to be dependent on several major factors.

\section{Age}

The older they were, the more likely that they would have problems with taking the medications. However, these older participants also tended to perceive low literacy less of a problem as they would be more likely to be seeking help from others.

\section{Gender}

Females tended to find low literacy a problem when compared to males. This was especially so when they had to look for new health care facilities such as hospitals and clinics.

\section{Chronic illnesses}

Those who were suffering from chronic illnesses such as diabetes or hypertension had often been taking the same medications and visiting the same clinics for a while. Therefore they tended to find low literacy less of a problem.

Lai 4: I am taking more than ten pills each day: pills for hypertension, for pain, for gout, and for my swelling... a total of sixteen pills. I take two of each every morning.

Interviewer: How can you remember...

Lai 4: I can remember. They are the same everyday.
Interviewer: You can remember which pills are for what purpose.

Lai 4: I can. I have been taking the same pills for a few years. I only need to remember the same ones.

(Individual Interview 3, text units 112-119)

\section{Attitudes towards self}

Those who had low self-esteem tended to think it was not a problem. Even if it were, they felt it was their own problem which they themselves should be held responsible.

Interviewer: You took your medicines like that for ten years, and only discovered that you did not take it properly recently.

Chan 1: The doctor asked me how I took my medicines. I told him that I took them once in the morning, and in the afternoon...

Lai 1: And nothing went wrong for such a long time?

Chan 1: No. That's why I said I have a "beggar's life"! [which is a strong implication of low self-esteem] (laughed) The doctor said, "It is lucky that you did not die of that. Those medicines are toxic. How can you take them in such a way?" I said, "I won't die! Mine is a 'beggar's life'. I haven't yet lived long enough as a 'beggar'! "

(Focus Group1, text units 158-161)

\section{How do the patients cope with their low literacy?}

Most of these patients with low literacy tended to rely on themselves to overcome most of their difficulties. They would try to remember the shape and colours of the medications that they had to take. They also often used symbols to help them remember whether they were for mornings (by drawing a sun) or evenings (by drawing a half moon).

Interviewer: Have you ever forgotten about which pill is which, and then took the wrong medicines since you cannot read?

Lee 2: No, I haven't. I can recognise them. They are of different colours.

(Individual Interview 5, text units 169-170)

Ma 1: He [the doctor] drew a sun [on the medicine bag] to represent that the pills are to be taken in the morning. Now I have bought some small boxes, those with compartments. I separate different pills in different compartments. 
(Focus Group 2, text unit 219)

Many also relied on their family members to help with their medications or visiting clinical places. They might ask their children to write down the name of the place that they had to go. Some would be quite prepared to seek help from people that they didn't know. Others feared that they might be taken advantaged of if they disclosed their poor literacy. Hence, they would not just ask anybody in the street, but would choose to ask people whom they felt safe with such as shopkeepers or drivers. However, some could recall experiences of discrimination.

Lee 3: I had just had breakfast with my relatives. Then we went for a stroll. There were a few of them, a few girls. [Since we weren't quite sure where we were,] my relatives asked them, "Miss, where is this place? Where does this bus go to?" They said, "Can't you tell? Anyone born in Hong Kong will be able to tell! Are you illegal immigrants?" They were not speaking to me, but to my relatives whom I was accompanying. It was not right for them to say so.

(Individual Interview 6, text unit 55)

As for health care workers, most participants felt better explanation was most important. They, however, did not usually actively seek help from them because they tended to think it was not the responsibility of health care workers to help them on matters relating to their low literacy.

Interviewer: When you encounter difficulties or inconveniences due to your low literacy, how can the doctors and nurses help you?

Ma 1: It's difficult for them to help. The difficulties are caused by our own stupidity. They have their own way of dealing with matters. We should not ask them to change their way to suit us.

Leung 1: I agree.

(Focus Group 2, text units 322-324)

Interviewer: [When you were presented with those written health information,] did you ask the doctor, "Can you explain it to me? I cannot read."

Yeung 2: I dared not. He wouldn't have the time. He could only afford the time for doctoring. He would not have the time to explain that to me. At most... say matters related to my heart disease...

Interviewer: Do you mean that you would only ask the doctor on matters directly related to your illnesses? For other things like those health information you mentioned, you would not ask him.

Yeung 2: That's right.

(Individual Interview 8, text units 203-206)

While some of the participants could recall incidents when they felt they were being ill-treated because of their low literacy, most of them however found better attitudes among staff in recent years. They all emphasised these improved attitudes would help them a lot in coping with their poor literacy problems. One of the participants recalled how her doctor helped her overcome the problem by drawing symbols for her.

Ma 1: There was a time when my children were not in town. I couldn't read it. So I brought it to Dr. X and asked him to read it for me. I said, "Doctor, I can't do it. Please help me." He drew me a sun and told me that those medicines were to be taken in the morning. He said only one kind of medicine was to be taken in the afternoon. So that was what I did - asking the private doctor to read it for me.

Interviewer: He drew a sun to illustrate that the medicine was to be taken in the morning. What did he draw to represent the afternoon?

Ma 1: I didn't have to take many medicines in the afternoon; only one pill for diabetes. That one I could recognize.

Interviewer: You only took one pill in the afternoon. The others were all to be taken in the morning.

Ma 1: There were many kinds of medicines [to be taken in the morning]. Thus I asked the doctor to draw me a symbol.

Interviewer: Did he draw it on each and every pack?

Ma 1: He did. He drew a sun on each and every pack.

(Focus Group 2, text units 201-213)

\section{Written health information}

Some participants encountered occasions when they were given written health information. In most cases, they would bring the written information home and asked their family members to read it for them. They usually regarded the information not essential so they didn't mind if the doctors or nurses did not specifically explain the content of the information. However, one participant recalled a case that she saw an old woman crying since she 
was asked to go home and read the information by herself.

Lee 3: There are so many patients. How can they [the medical staff] have the time to talk to you in details? You ask them an extra question and they would say, "It is all written here. Don't you understand? Go home and read it."

Interviewer: They don't have the patience to explain it to you.

Lee 3: They don't explain. Worse still, they would scold us.

Interviewer: They would scold you, and would ask you to read it by yourself.

Lee 3: They would say, "Go home and ask someone to read it for you." One time an old woman was crying when she was walking out of the consultation room.

Interviewer: Was she?

Lee 3: I said, "Don't cry. Take it to your neighbours and ask them to read it for you. Ask some young men to read it for you." She said, "Being an illiterate is so poor! " I said, " I am also an illiterate. Don't think about it so much." I am usually the one who tries to console other people. I myself understand the hardship of being an illiterate. So I try to console the others.

(Individual Interview 6, text units 250-256).

Another participant commented:

Lee 2: [Giving me the written information] is just like giving me a blank piece of paper.

(Individual Interview 5, text unit 343).

\section{Discussion}

The aim of this study was to explore how low literate Chinese patients cope with their health literacy needs. Qualitative methods were used because they allowed an indepth exploration of a rather sensitive issue. The data obtained in this study would not have been possible if a questionnaire survey methodology were to be adopted. The fact that one of the authors (TPL) has practiced in the community for over eight years allowed us to recruit subjects with diverse demographic background.

For those of us who can read, it may be surprising to learn that, as shown in this study, only some Chinese patients with poor literacy readily felt any problems associated with it, even in urban environment like Hong Kong. Many others didn't think it was a problem at all. It is therefore quite possible that we could be looking after patients with low literacy and not know it. A previous study in the US has shown that patient educational status is not a valid indicator of reading ability [12]. Appearance is also an unreliable basis on which to judge ability to read and understand health instructions [13]. Patients with poor literacy may not follow instructions, which was also happening among participants of this study, but is vital to good medical care $[14,15]$.

Our findings suggest that factors such as age, gender, chronic illnesses, and attitudes towards self affect participants' perception of their low literacy. These are therefore some of the important 'cues' to alert health professionals that they could be dealing with a Chinese patient with low literacy. Special efforts may therefore be needed to ensure the literacy skills of such patients are checked.

This study revealed the coping strategies that some of the participants adopted, for example, drawing simple symbols or recognizing simple numbers to help with the timing of taking the medications and the dosages. These strategies could well be useful for low literacy patients in other parts of the world, especially overseas Chinese patients with low command of the local languages of their place of residence. However, the most important help to these patients with low literacy, as identified in this study, was better explanation by health care workers. This once again confirms the importance of effective communication between patients and health professionals.

\section{Limitations of the study}

Most of the participants in this study were females over 60 years of age. This was because most of the low literacy people in Hong Kong are elderly and/or females these days. Although it is possible that a younger sample may have revealed different findings, it is the data from the most representative group i.e. elderly females, which is most important to this study.

Another issue was the possible influence that one of the authors (TPL), as the local family doctor, might have had on the participants. It was for this reason that a trained research assistant was recruited to conduct the interviews in order to minimize the bias and anxiety that some of the participants might have had of their family doctors in an unfamiliar non-clinical setting. An analysis of the data from those who were known and unknown to TPL also did not reveal any significant differences.

\section{Conclusions}

It is highly relevant for health care workers to be aware of the low literacy status of their patients and to explain information so that patients understand it. 


\section{Competing interests}

None declared

\section{Authors' contributions}

TPL fostered the research idea, designed the project, analysed the data, and drafted the manuscript. YHC discussed with TPL the research idea, designed the project and drafted the manuscript. YLC interviewed the participants, transcribed the interviews and analysed the data. All authors read and approved the final manuscript.

\section{Acknowledgements}

This work was made possible by a grant from the Research and Conference Grants of the University of Hong Kong.

\section{References}

I. Hong Kong Census and Statistics Department: 200I Population Census. Main Report - Volume I. Hong Kong: Printing Department, Hong Kong SAR Government. 200I.

2. Baker DW, Parker RM, Williams MD, Pitkin K, Parikh NS, Coates W, Imara $M$ : The health care experience of patients with low literacy. Arch Fam Med 1996, 5:329-334.

3. Weiss BD, Hart G, McGee DL, D'Estelle S: Health status of illiterate adults: relation between literacy and health status among persons with low literacy skills. J Am Board Fam Pract 1992, 5:257-64.

4. Powers RD: Emergency department patient literacy and the readability of patient-directed materials. Ann Emerg Med 1988, 17:124-126.

5. Jaycox S: Smoking literature and literacy and the readability of smoking education literature. Am J Public Health 1989, 79:204-206.

6. Gazmararian JA, Baker DW, Williams MV, Parker RM, Scott TL, Green DC, Fehrenbach SN, Ren J, Koplan JP: Health literacy among medicare enrolees in a managed care organization. JAMA 1999, 281:545-55I.

7. American Medical Association: Ad hoc committee on health literacy for the Council on Scientific Affairs. Health Literacy Report of the Council on Scientific Affairs. JAMA 1999, 281:552-557.

8. Boisaubin EV, Dresser R: Informed consent in emergency care: illusion and reform. Ann Emerg Med 1987, 16:62-67.

9. Rossof $\mathrm{AH}$ : Noncompliant, or illiterate? Lancet 1989, I:362.

10. Kraut AM: Healers and strangers. Immigrant attitudes toward the physician in America - a relationship in historical perspective. JAMA 1990, 263:|807-I8II.

II. Strauss A, Corbn J: Basics of qualitative research. Grounded theory procedures and techniques. London: Sage 1990.

12. Davis TC, Crouch MA, Long SW, Jackson RH, Bates P, George RB, Bairnsfather LE: Rapid Assessment of literacy levels of adult primary care patients. Fam Med I991, 23(6):433-435.

13. Doak CC, Doak LG, Root JH: Teaching patients with low literacy skills. Philadelphia, JB Lipincott 1985.

14. Sands D, Holman E: Does knowledge enhance patient compliance? J Gerontol Nurs 1985, I I:23-29.

15. Vermeire E, Hearnshaw H, Van Royen P, Denekens J: Patient adherence to treatment: three decades of research. A comprehensive review. J Clin Pharmacy and Therapeutics 200I, 26:33|-342.

\section{Pre-publication history}

The pre-publication history for this paper can be accessed here:

http://www.biomedcentral.com/1471-2458/4/14/prepub http.//www.biomedcentral.com/1471-2458/4/14 